\title{
Cerebrospinal Fluid Lactate Concentration to Differentiate Bacterial from Viral Meningitis in Children
}

\author{
Ton Nu van Anh ${ }^{1 *}$, Nguyen Huu Son², Mai Thi Hien Uyen², Nguyen Thi Diem Chi $^{2}$, Nguyen Thi \\ Hong Duc ${ }^{2}$ and Tran Vinh Phu ${ }^{1}$ \\ ${ }^{1}$ Pediatric Department, Hue University of Medicine and Pharmacy, Vietnam \\ ${ }^{2}$ Pediatric Center, Hue Central Hospital, Vietnam
}

*Corresponding author: Ton Nu van Anh, Pediatric Department, Hue University of Medicine and Pharmacy, Vietnam

\section{ARTICLE INFO}

Received: 幽 February 26, 2019

Published: 蔧 March 12, 2019

Citation: Ton $\mathrm{Nu}$ van A, Nguyen Huu S, Mai Thi Hien U, Nguyen Thi Diem C, Nguyen Thi Hong D, et al., Cerebrospinal Fluid Lactate Concentration to Differentiate Bacterial from Viral Meningitis in Children. Biomed J Sci \& Tech Res 15(5)-2019. BJSTR. MS.ID.002766.

Abbreviations: BM: Bacterial Meningitis; AM: Acute Viral Meningitis; RBC: Red Blood Cells; NPV: Negative Predictive Value; ROC: Receiver-Operator Curve

\begin{abstract}
Objective: To define an optimal CSF lactate concentration that can be called significant for the differentiation bacterial meningitis from viral meningitis in children.

Methods: Children with clinical findings compatible with meningitis were studied. CSF lactate and other conventional CSF parameters were recorded. We determined the optimum cutoff point for CSF lactate using receiver-operator curve (ROC) analysis.

Results: We identified 54 had bacterial meningitis. Children with bacterial meningitis had a higher median CSF lactate level [6.5 mmol/l, interquartile range (IQR) 2.3-10.7 mmol/l bacterial meningitis vs. $2.1 \mathrm{mmol} / \mathrm{l}$, IQR $1.3-2.9 \mathrm{mmol} / \mathrm{l}$ viral meningitis]. A CSF lactate cutoff point of $3.0 \mathrm{mmol} / \mathrm{l}$ had a sensitivity of $87.0 \%$ (95\% CI $66.4-97.2 \%$ ), a specificity of $87.1 \%$ (95\% CI $70.2-96.4 \%$ ) for bacterial meningitis. The CSF lactate concentration is a better marker compared to other conventional markers including CSF glucose and CSF total number of leukocytes.
\end{abstract}

Conclusion: In combination with a validated meningitis clinical prediction rule, the CSF lactate level can be used to distinguish between bacterial and viral meningitis in children.

Keywords: Bacterial Meningitis; Viral Meningitis; Cerebrospinal Fluid; Lactate

\section{Introduction}

Accurate and rapid diagnosis of acute bacterial meningitis (BM) is essential because disease outcome depends on immediate initiation of appropriate antibiotic therapy [1]. BM should be treated promptly with antibiotics, whereas acute viral meningitis (AM) is usually self-limiting. However, differentiating BM from AM may be challenging for clinicians because the symptoms and laboratory assays are often similar and overlapping. In addition, classical clinical manifestations of BM in infants and children are usually difficult to recognize because of the absence of signs of meningeal irritation and because of delayed elevation of intracranial pressure. Combination of present CSF variables (proteins, glucose, leucocytes count and ratio of CSF/serum glucose) has been suggested effective in differentiating acute viral meningitis from bacterial meningitis
$[2,3]$. However, there are serious limitations of the above variables in diagnosing and differentiating bacterial and viral meningitis. The gold standard for the diagnosis for bacterial meningitis is culture, which requires several days to return results [4,5]. Rapidly available biomarkers such as cerebrospinal (CSF) lactate have been studied to distinguish bacterial from viral meningitis before the results of bacterial cultures become available. CSF lactate levels are high in children with bacterial meningitis as lactate is produced by both bacterial anaerobic metabolism as well as ischemic brain tissue [6]. CSF lactate is produced by anaerobic metabolism and the level increases in any condition which causes decrease in oxygen supply to the brain and there is no correlation with serum lactate level [7]. In our retrospective cohort of children with meningitis, we 
sought to establish the optimal CSF lactate cutoff point to accurately distinguish between bacterial and viral meningitis.

\section{Materials and Methods}

\section{Patients}

We performed a retrospective cohort study of children with meningitis between 1 month and 15 years of age who presented to Pediatric Center of Hue Central Hospital during 2016 and 2018. The study was approved by the hospital ethics committee. The inclusion criteria were: children who had clinical findings consistent with meningitis (e.g., fever, headache, vomiting or nausea, and neck stiffness) along with CSF white blood cells (WBC) $\geq 10$ cells $/ \mu \mathrm{l}$ [corrected for the presence of CSF red blood cells (RBC) using a standard 1:500 ratio of leukocytes to erythrocytes] and who had both a CSF lactate and CSF culture obtained. We further limited our study population to those children who had CSF lactate obtained by the treating clinician. Exclusion criteria were children with any of the following: critical illnesses, any purpura, presence of a ventricular shunt or recent neurosurgery, immunosuppression and other bacterial infections requiring parenteral antibiotics. We reviewed the medical records for all eligible children and abstracted relevant clinical and laboratory factors for all study patients. The CSF lactate level was measured by the hospital clinical laboratory using standard enzymatic methods. We defined a case of bacterial meningitis as a child with either a positive CSF culture or CSF pleocytosis with a positive blood culture for a bacterial pathogen [8]. We defined a case of viral meningitis as a child with meningitis who had not received antibiotics prior to diagnostic lumbar puncture who had a negative CSF bacterial culture [8].

\section{Statistical Analysis}

We first selected a range of cutoff points for the CSF lactate biomarker to distinguish bacterial from viral meningitis. We reported the sensitivity, specificity and negative predictive value (NPV) for bacterial meningitis of each CSF lactate cutoff point. Next, we generated a receiver-operator curve (ROC) to visually represent the trade-off between sensitivity and specificity. We utilized ROC curve analysis to select the optimal CSF lactate cutoff point to minimize both the number of false positives (children with viral meningitis with CSF lactate above the chosen cutoff point) as well as false negatives (children with bacterial meningitis with CSF lactate below the cutoff point). A Mann-Whitney U-test was performed to compare lactate levels between children with bacterial and viral meningitis. We used SPSS version 19.0 for all statistical analyses.

\section{Results}

A total of 54 (23 bacterial and 31 viral) pediatric patients fulfilled the inclusion criteria. the mean age was 60.5 months [median 40.5 months; interquartile range (IQR) 10-85 months], and 37 (68.5\%) were male. Children with bacterial or viral meningitis had CSF lactate concentrations (Table 1). Each step-wise increase in the CSF lactate cutoff point lowered the sensitivity, but increased the specificity for bacterial meningitis (Table 2). Next we present a ROC curve for CSF lactate for bacterial meningitis (Figure 1). Using ROC analysis, we selected an optimal cutoff point for CSF lactate of $3.0 \mathrm{mmol} / \mathrm{l}$ to distinguish between bacterial and viral meningitis [area under the curve $0.887 ; 95 \%$ confidence interval (CI) 0.771 to 0.957$]$. CSF lactate $\geq 3.0 \mathrm{mmol} / \mathrm{l}$ had a sensitivity of $87.0 \%$ (95\% CI 66.4 - 97.2\%), a specificity of $87.1 \%$ (95\% CI 70.2 - 96.4\%) for bacterial meningitis. The receiver-operating curve for CSF lactate to distinguish bacterial from viral meningitis has the greatest AUC compared to that of the other CSF biomaker such as leucocytes count (AUC 0.87), glucose (AUC 0.290) (Table 3).

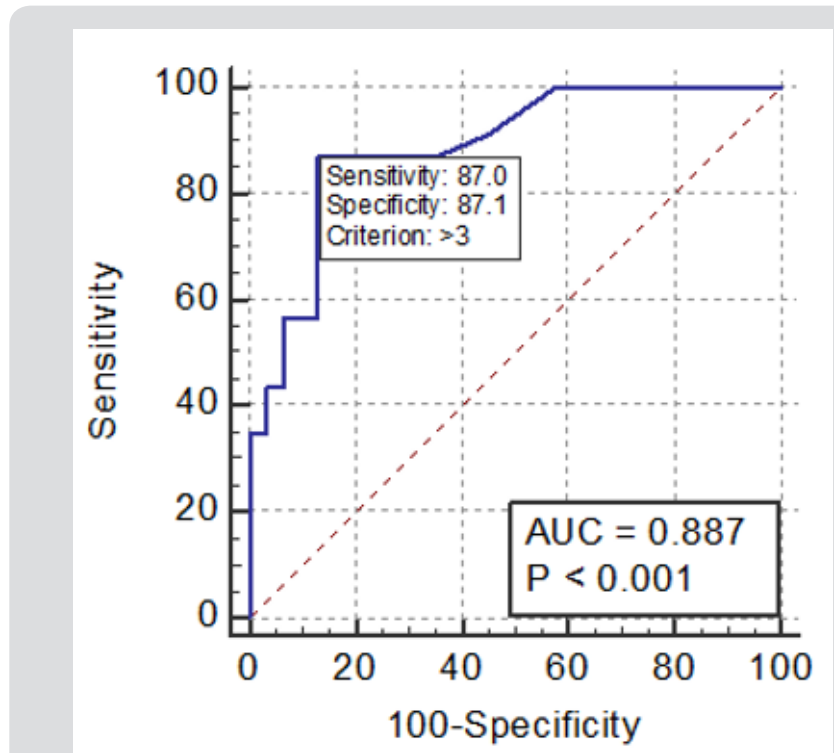

Figure 1: Receiver-operating curve for CSF lactate to distinguish bacterial from viral meningitis.

Table 1: CSF lactate concentration in children with bacterial and viral meningitis.

\begin{tabular}{|c|c|c|}
\hline CSF Biomaker & AUC & p-value \\
\hline Leucocytes count & 0.870 & $<0.01$ \\
\hline Glucose & 0.290 & $<0.01$ \\
\hline Lactate & 0.887 & $<0.001$ \\
\hline
\end{tabular}


Table 2: The diagnostic accuracy of CSF lactate for bacterial meningitis by cutoff point.

\begin{tabular}{|c|c|c|c|c|c|c|}
\hline $\begin{array}{c}\text { CSF lactate } \\
\text { (mmol/1) }\end{array}$ & Sensitivity & $\mathbf{9 5 \%}$ CI & Specificity & $\mathbf{9 5 \%}$ CI & +LR & -LR \\
\hline$\geq 1.5$ & 100.00 & $85.2-100.0$ & 0.00 & $0.0-11.2$ & 1.00 & \\
\hline$>2$ & 100.00 & $85.2-100.0$ & 41.94 & $24.5-60.9$ & 1.72 & 0.00 \\
\hline$>2.1$ & 91.30 & $72.0-98.9$ & 54.84 & $36.0-72.7$ & 2.02 & 0.16 \\
\hline$>2.2$ & 86.96 & $66.4-97.2$ & 64.52 & $45.4-80.8$ & 2.45 & 0.20 \\
\hline$>3$ & 86.96 & $66.4-97.2$ & 87.10 & $70.2-96.4$ & 6.74 & 0.15 \\
\hline$>5.7$ & 56.52 & $34.5-76.8$ & 87.10 & $70.2-96.4$ & 4.38 & 0.50 \\
\hline$>6.1$ & 56.52 & $34.5-76.8$ & 93.55 & $78.6-99.2$ & 8.76 & 0.46 \\
\hline$>6.7$ & 43.48 & $23.2-65.5$ & 93.55 & $78.6-99.2$ & 6.74 & 0.60 \\
\hline$>7.1$ & 43.48 & $23.2-65.5$ & 96.77 & $83.3-99.9$ & 13.48 & 0.58 \\
\hline$>7.9$ & 34.78 & $16.4-57.3$ & 96.77 & $83.3-99.9$ & 10.78 & 0.67 \\
\hline$>8$ & 34.78 & $16.4-57.3$ & 100.00 & $88.8-100.0$ & & 0.65 \\
\hline$>13.3$ & 0.00 & $0.0-14.8$ & 100.00 & $88.8-100.0$ & & \\
\hline
\end{tabular}

Table 3: Comparison of AUC of CSF lactate with other conventional CSF biomaker for distinguishing bacterial from viral meningitis.

\begin{tabular}{|c|c|c|}
\hline CSF Biomaker & AUC & p-value \\
\hline Leucocytes count & 0.870 & $<0.01$ \\
\hline Glucose & 0.290 & $<0.01$ \\
\hline Lactate & 0.887 & $<0.001$ \\
\hline
\end{tabular}

\section{Discussion}

In our retrospective cohort of children with meningitis, CSF lactate $\geq 3.0 \mathrm{mmol} / \mathrm{l}$ accurately distinguished between bacterial and viral meningitis. This is similar to the report of Eduardo Mekitarian Filho et with 451 children of whom 40 (9\%) had bacterial meningitis. Children with bacterial meningitis had a higher median CSF lactate level [9.6 mmol/l, interquartile range (IQR) 3.2-38.5 mmol/l bacterial meningitis vs. $2.0 \mathrm{mmol} / \mathrm{l}$, IQR 1.2-2.8 $\mathrm{mmol} / \mathrm{l}$ viral meningitis]. A CSF lactate cutoff point of $3.0 \mathrm{mmol} / \mathrm{l}$ had a sensitivity of 95\% [95\% confidence interval (CI) 83-99\%), specificity of $94 \%$ (95\% CI 90-96\%) and negative predictive value of 99.3\% (95\% CI 97.7-99.9\%) for bacterial meningitis [9]. The AUC of CSF lactate concentration was 0.887, indicating an excellent level of overall accuracy. The overall performance was highest for the CSF lactate concentration compared to the performances of the other conventional markers (CSF glucose, CSF total number of leukocytes), which was in good agreement with previous literature [10]. CSF lactate is less useful if it has a low concentration, but the assay is supportive if it is positive, especially if the diagnosis was otherwise not conclusive. In such cases, increased CSF lactate should be considered a sign of BM. Because of the lactate assay, several BM patients with elevated CSF lactate and minimal CSF abnormalities have been treated with antibiotics prior to culture test results $[11,12]$.

The measurement of CSF lactate concentration is a simple, rapid, inexpensive assay, takes just 15 minutes, and can be performed at the bedside. In addition, the CSF lactate concentration is useful during the course of treatment, because a rapid CSF lactate decrease is indicative of good prognosis [13]. Since the CSF lactate concentration is not specific for BM, the results of this assay should be interpreted in parallel with clinical findings and the results of conventional assays including CSF concentrations of protein, cells, glucose, and a microbiological examination of CSF. The cut-off value for CSF lactate concentration ranges from 2.1 to $4.44 \mathrm{mmol} / \mathrm{L}$, suggesting a variance between instrument, hospital labs, and the method. Therefore, every center should set its own cut-off value for CSF lactate concentration. Another disadvantage of CSF lactate is that it is not useful in the choice of antibiotic selection, which must be based on the results of microscopic examination of a smear or culture for bacteria, as well as the other clinical data [14].The mechanism of the increased concentration of lactate in the CSF of patients with BM is not clear, but it has been linked with anaerobic glycolysis of brain tissue due to a decrease cerebral blood flow and oxygen uptake $[15,16]$. Additionally, the concentration of CSF lactate is independent of serum lactate, probably due to its ionized state that crosses the blood-CSF barrier at a very slow rate [17], suggesting another advantage over CSF glucose assay [18].

Two recent meta-analyses evaluated the ability of CSF lactate to distinguish aseptic from bacterial meningitis [14,19]. These two studies included 38 unique studies with between 15 and 201 patients per study. Using a CSF lactate cutoff point between 2.1 and $4.4 \mathrm{mmol} / \mathrm{l}$, the aggregated sensitivity of CSF lactate for bacterial meningitis was $93 \%$ or $96 \%$ and specificity $94 \%$ or $96 \%$, respectively (Table 4). The management of children with meningitis may differ in resource-poor settings asthe incidence of bacterial meningitis may be considerably higher and clinicians may have limited access to diagnostic laboratories [20]. Available handheld testing platforms can provide point-of-care testing for CSF 
lactate. In a small study conducted in Uganda, CSF lactate analysis using a hand-held device had good sensitivity and specificity for bacterial meningitis [21]. Larger, likely multi-centered, studies are needed to further evaluate the diagnostic accuracy of CSF lactate in resource-poor settings. In order to compare the diagnostic accuracy of the CSF lactate concentration and other conventional markers for diagnosis of BM, data were extracted from the 25 selected articles only if the study had on the same set of specimens a parallel analysis of CSF lactate and a conventional marker [22-26]. Since conventional markers were used as the diagnostic criteria of BM, only BM patients with confirmed diagnosis were extracted in this analysis. In the present study, for diagnosis of BM, five studies performed head to head comparisons of CSF lactate versus CSF glucose, four versus the CSF/plasma glucose quotient, seven versus CSF protein, five versus CSF total number of leukocytes, one versus percentages of granulocytes, and one versus CSF number of granulocytes. However, TB meningitis patients and partially treated BM patients could not be excluded from the conventional markers assays. Therefore, in a secondary meta-analysis these patients were included in the BM group. Higher DOR values were observed with the CSF lactate level than with the conventional markers in all studies except for one study for the CSF protein assay and one study for total number of leukocytes [26-30]. Since DOR values of the CSF lactate concentration, CSF glucose level, CSF/plasma glucose quotient, and CSF total number of leukocytes were found to be constant (data not shown), symmetrical SROC fitting by a random effects model was performed for these assays [14]. The present study had a number of limitations. Only a single measurement of lactate was made, upon hospital admission; repeat assessments to monitor treatment and response were not performed.

Table 4: Cut-off of CSF lactate to distinguish bacterial from viral meningitis according to other studies.

\begin{tabular}{|c|c|c|c|c|c|c|c|c|c|}
\hline \multirow[t]{2}{*}{ Study (ref) } & \multirow[t]{2}{*}{ Year } & \multirow[t]{2}{*}{ Country } & \multicolumn{2}{|c|}{ Number of patients } & \multirow[t]{2}{*}{ Cut-off (mmol/L) } & \multicolumn{4}{|c|}{ Test Results } \\
\hline & & & BM & AM & & TP & FP & FN & TN \\
\hline $\begin{array}{c}\text { Cameron } \\
{[18]}\end{array}$ & 1993 & UK & 11 & 9 & 4.1 & 11 & 0 & 0 & 9 \\
\hline Donald [20] & 1986 & S. Africa & 43 & 23 & 2.85 & 40 & 0 & 3 & 23 \\
\hline Nelson [21] & 1986 & Sweden & 11 & 28 & 2.4 & 11 & 3 & 0 & 25 \\
\hline Lester A [22] & 1986 & Singapore & 22 & 54 & 2.78 & 19 & 8 & 3 & 46 \\
\hline $\begin{array}{c}\text { Ruuskanen } \\
{[23]}\end{array}$ & 1985 & Finland & 32 & 30 & 3 & 30 & 2 & 2 & 28 \\
\hline $\begin{array}{c}\text { Vanprapar } \\
{[24]}\end{array}$ & 1983 & Thailand & 22 & 18 & 3.89 & 20 & 0 & 2 & 18 \\
\hline Mandal [25] & 1983 & UK & 20 & 59 & 3.9 & 20 & 5 & 0 & 54 \\
\hline Knight [26] & 1981 & US & 68 & 20 & 3.3 & 68 & 3 & 0 & 17 \\
\hline $\begin{array}{c}\text { Controni } \\
{[27]}\end{array}$ & 1977 & US & 55 & 15 & 2.78 & 53 & 0 & 2 & 15 \\
\hline Bland [28] & 1974 & US & 13 & 25 & 4.44 & 12 & 0 & 1 & 25 \\
\hline
\end{tabular}

\section{Conclusion}

The findings of this study indicated that for discrimination of BM from AM, the CSF lactate concentration is a good single indicator and a better marker compared to other conventional markers including CSF glucose, and CSF total number of leukocytes. In combination with other validated clinical prediction models, CSF lactate can assist with clinical decision-making for children with meningitis.

\section{References}

1. Chauhan D, Mokta K, Kanga A, Grover N (2018) Epidemiology, clinical profile and role of rapid tests in the diagnosis of acute bacterial meningitis in children (aged 1-59 months). Neurol India 66(4): 10451049.

2. Sanaei Dashti A, Alizadeh S, Karimi A, Khalifeh M, and Shoja SA (2017) Diagnostic value of lactate, procalcitonin, ferritin, serum-C-reactive protein, and other biomarkers in bacterial and viral meningitis: A crosssectional study. Medicine (Baltimore) 96(35): e7637.

3. Bonsu BK, Harper MB (2004) Differentiating acute bacterial meningitis from acute viral meningitis among children with cerebrospinal fluid pleocytosis: a multivariable regression model. Pediatr Infect Dis J 23(6): 511-517.
4. Jansen GJ, Mooibroek M, Idema J, Harmsen HJ, Welling GW, et al. (2000) Rapid identification of bacteria in blood cultures by using fluorescently labeled oligonucleotide probes. J Clin Microbiol 38(2): 814-817.

5. Poppert S, Essig A, Stoehr B, Steingruber A, Wirths B, et al. (2005) Rapid diagnosis of bacterial meningitis by real-time PCR and fluorescence in situ hybridization. J Clin Microbiol 43(7): 3390-3397.

6. Guerra Romero L, Tauber MG, Fournier MA, Tureen JH (1992) Lactate and glucose concentrations in brain interstitial fluid, cerebrospinal fluid, and serum during experimental pneumococcal meningitis. J Infect Dis 166(3): 546-550.

7. Salord F, Boussaid O, Eynard N, Perret C, Grando J, et al. (1994) Value of $\mathrm{D}(-)$ lactate determination for the fast diagnosis of meningitis after craniotomy. An initial study. Ann Fr Anesth Reanim 13(5): 647-653.

8. Nigrovic LE, Kuppermann N, Macias CG, Cannavino CR, Moro Sutherland DM, et al. (2007) Clinical prediction rule for identifying children with cerebrospinal fluid pleocytosis at very low risk of bacterial meningitis. JAMA 297(1): 52-60.

9. Mekitarian Filho E, Horita SM, Gilio AE, Nigrovic LE (2014) Cerebrospinal fluid lactate level as a diagnostic biomarker for bacterial meningitis in children. Int J Emerg Med 7(1): 14.

10. Kleine TO, Zwerenz P, Zofel P, Shiratori K (2003) New and old diagnostic markers of meningitis in cerebrospinal fluid (CSF). Brain Res Bull 61(3): 287-297. 
11. Gastrin B, Briem H, Rombo L (1979) Rapid diagnosis of meningitis with use of selected clinical data and gas-liquid chromatographic determination of lactate concentration in cerebrospinal fluid. J Infect Dis 139(5): 529-533.

12. Ponka A, Ojala K, Teppo AM, Weber TH (1983) The differential diagnosis of bacterial and viral meningitis using cerebrospinal fluid laboratory tests. Infection 11(3): 129-131.

13. Nazir M, Wani WA, Malik MA, Mir MR, AshrafY, et al.(2018) Cerebrospina fluid lactate: a differential biomarker for bacterial and viral meningitis in children. J Pediatr (Rio J) 94(1): 88-92.

14. Huy NT, Thao NT, Diep DT, Kikuchi M,Zamora J, et al. (2010) Cerebrospinal fluid lactate concentration to distinguish bacterial from viral meningitis: a systemic review and meta-analysis. Crit Care 14(6): R240.

15. Menkes JH (1969) The causes for low spinal fluid sugar in bacterial meningitis: another look. Pediatrics 44(1): 1-3.

16. Paulson OB, Hansen EL, Kristensen HS, Brodersen P (1972) Cerebral blood flow, cerebral metabolic rate of oxygen and CSF acid-base parameters in patients with acute pyogenic meningitis and with acute encephalitis. Acta Neurol Scand Suppl 51: 407-408.

17. Posner JB, Plum F (1967) Independence of blood and cerebrospinal fluid lactate. Arch Neurol 16(5): 492-496.

18. Cameron PD, Boyce JM, Ansari BM (1993) Cerebrospinal fluid lactate in meningitis and meningococcaemia. J Infect 26(3): 245-252.

19. Sakushima K, Hayashino Y, Kawaguchi T, Jackson JL, Fukuhara S (2011) Diagnostic accuracy of cerebrospinal fluid lactate for differentiating bacterial meningitis from viral meningitis: a meta-analysis. J Infect 62(4): 255-262.

20. Donald PR, Malan C (1986) Cerebrospinal fluid lactate and lactate dehydrogenase activity in the rapid diagnosis of bacterial meningitis. $S$ Afr Med J 69(1): 39-42

21. Nelson N, Eeg-Olofsson O, Larsson L, Ohman S (1986) The diagnostic and predictive value of cerebrospinal fluid lactate in children with meningitis. Its relation to current diagnostic methods. Acta Paediatr Scand 75(1): 52-57.

\section{ISSN: 2574-1241}

DOI: 10.26717/BJSTR.2019.15.002769

Ton Nu van Anh. Biomed J Sci \& Tech Res

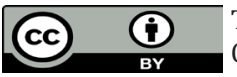

This work is licensed under Creative Commons Attribution 4.0 License

Submission Link: https://biomedres.us/submit-manuscript.php
22. Lester A, Stilbo I, Bartels P, Bruun B (1985) Value of CSF lactate in the differential diagnosis between bacterial meningitis and other diseases with meningeal involvement. Acta Pathol Microbiol Immunol Scand B 93(1): 21-25.

23. Ruuskanen 0 , Stahlberg ML, Korvenranta H, Nikoskelainen J, Irjala $\mathrm{K}$ (1985) CSF lactate in bacterial meningitis with minimal CSF abnormalities. Acta Paediatr Scand 74(2): 292-293.

24. Vanprapar N, Chavalittamrong B, Limsathayurat N (1983) Cerebrospinal fluid lactate level in childhood purulent meningitis. Southeast Asian J Trop Med Public Health 14(2): 186-190.

25. Mandal BK, Dunbar EM, Hooper J, Parker L (1983) How useful is cerebrospinal fluid lactate estimation in differential diagnosis of meningitis? J Infect 6(3): 231-237.

26. Knight JA, Dudek SM, Haymond RE (1981) Early (chemical) diagnosis of bacterial meningitis--cerebrospinal fluid glucose, lactate, and lactate dehydrogenase compared. Clin Chem 27(8): 1431-1434.

27. Controni G, Rodriguez WJ, Hicks JM, Ficke M, Ross S, et al. (1977) Cerebrospinal fluid lactic acid levels in meningitis. J Pediatr 91(3): 37984.

28. Bland RD, Lister RC, Ries JP (1974) Cerebrospinal fluid lactic acid level and $\mathrm{pH}$ in meningitis. Aids in differential diagnosis. Am J Dis Child 128(2): 151-156.

29. Scarborough M, Thwaites GE (2008) The diagnosis and management of acute bacterial meningitis in resource-poor settings. Lancet Neurol 7(7): 637-648.

30. Majwala A, Burke R, Patterson W, Pinkerton R, Muzoora C, et al. (2013) Handheld point-of-care cerebrospinal fluid lactate testing predicts bacterial meningitis in Uganda. Am J Trop Med Hyg 88(1): 127-131.

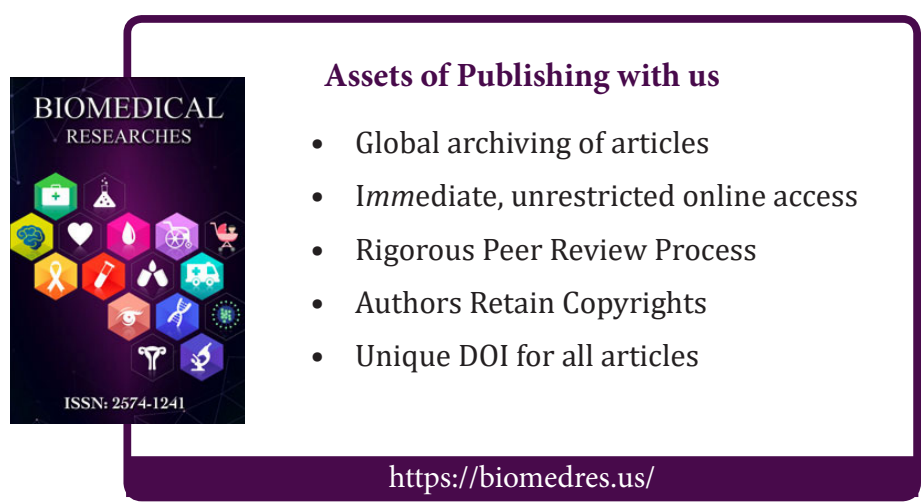

